\title{
FUNDAMENTOS TEÓRICOS E METODOLÓGICOS DA PRECARIZAÇÃO DO TRABALHO DOCENTE
}

\author{
Jussara Marques de Macedo ${ }^{1}$ \\ Miriam Morelli Lima²
}

\begin{abstract}
RESUMO: 0 artigo resulta da investigação sobre a precarização do trabalho docente. Objetiva-se analisar os fundamentos teórico-metodológicos da precarização do trabalho docente no Brasil a partir dos anos de 1990, articulando-os às políticas de formação. A pesquisa bibliográfica de caráter qualitativo se deu por meio da revisão de literatura e análise de fontes primárias e secundárias. Analisou-se o processo de intensificação da precariedade do trabalho docente no Brasil, em decorrência da adoção de novos modelos de gestão educacional pautados nos princípios da "Nova Gestão Pública". 0 resultado é que a contrarreforma da educação contribuiu para a precarização do trabalho docente e levou à efetivação de políticas de formação bem articuladas às orientações dos organismos internacionais. Conclui-se que tais mudanças fundamentam não apenas o trabalho, mas a formação, afastando-se, portanto, da perspectiva de educação para a emancipação humana.
\end{abstract}

Palavras-chave: Trabalho Docente - Formação Docente - Teoria e Método

\footnotetext{
${ }^{1}$ Doutora em Educação pela Universidade Federal Fluminense (UFF), Mestre em Educação e Licenciada em Pedagogia por esta mesma universidade. Atua como professora adjunta do Departamento de Administração Educacional da Faculdade de Educação da Universidade Federal do Rio de Janeiro (UFRJ). Tem experiência na área de Educação, com ênfase em Política Educacional, atuando principalmente nos seguintes temas: trabalho docente e políticas públicas. É membro do Coletivo de Estudos em Marxismo e Educação (COLEMARX/UFRRJ). E-mail: jussara0712@gmail.com

2 Doutora em Educação pela Universidade Estadual de Campinas (UNICAMP), Mestre em Educação pela Universidade de São Paulo (USP) e graduada em Pedagogia pela Universidade Federal do Espírito Santo (UFES). Atua como professora do Departamento de Teoria e Planejamento de Ensino do Instituto de Educação da Universidade Federal Rural do Rio de Janeiro (UFRRJ), atuando na área de planejamento, avaliação e gestão educacional. É Membro do Grupo de Estudos e Pesquisa em Diferenciação Sóciocultural (GEPEDISC/UNICAMP) e do Grupo de Pesquisa Trabalho Política e Sociedade (GTPS/UFRRJ), na linha de pesquisa Educação e Trabalho, desenvolvendo pesquisas principalmente nos seguintes temas: sociologia do trabalho, trabalho docente, gestão, avaliação e planejamento escolar e gestão e avaliação de sistemas educacionais. E-mail: morelli.miriam@gmail.com
} 


\title{
THEORETICAL AND METHODOLOGICAL FOUNDATIONS OF THE PRECARISATION OF TEACHING WORK
}

\begin{abstract}
The article results from research on the precariousness of teaching work. The objective of this study is to analyze the theoretical and methodological foundations of the precariousness of teaching work in Brazil from the 1990s on, linking them to training policies. A bibliographical research was carried out through literature review and analysis of primary and secondary sources. The process of intensifying the precariousness of teaching work in Brazil was analyzed, due to the adoption of new models of educational management based on the principles of "New Public Management". The result is that the counterreform of education contributed to the precariousness of teaching work and led to the implementation of training policies well articulated to the guidelines of international organizations. It follows that such changes ground not only the work, but the formation, moving away, therefore, from the perspective of education for human emancipation.
\end{abstract}

Keywords: Teaching Work - Teacher Training - Theory and Method

\section{Introdução}

0 artigo apresenta uma reflexão acerca do processo de intensificação da precariedade do trabalho docente no Brasil, em decorrência da adoção de novos modelos de gestão educacional pautados nos princípios da "Nova Gestão Pública". Seu objetivo é analisar os fundamentos sociais e políticos da precarização do trabalho docente no Brasil a partir dos anos 1990, relacionando-os às políticas de formação de professores.

Partimos do pressuposto de que, no campo educacional, a implementação de novos modelos de gestão se transformou em um modo eficaz de avaliar e controlar o trabalho docente, tomando como principal argumento o discurso da garantia da "qualidade" da educação. Nesse sentido, valoriza-se o domínio das Tecnologias da Informação e da Comunicação (TIC), o conhecimento tácito e a formação de novas competências por meio das políticas de formação para o trabalho docente no Brasil, especialmente a partir da promulgação da Lei 9.394/1996 - Lei de Diretrizes e Bases da Educação Nacional (LDB).

Trata-se de uma análise qualitativa a partir de análise de fontes bibliográficas primárias e secundárias. Para tal análise, tomamos como referência analítica o materialismo histórico e dialético, de modo que a análise do fenômeno da intensificação da precariedade do trabalho docente parte da sua aparência para chegar a sua essência (KOSIK, 1969), com a finalidade de capturar o fenômeno em sua totalidade. Isso nos possibilitou verificar que as exigências em torno do trabalho docente na educação básica, hoje, com base na lógica gerencialista, é 
resultado de processos pré-determinados na vida do trabalhador docente desde sua formação.

\section{Reestruturação do trabalho docente}

O mundo passou por significativas alterações que marcaram o final do século XX e início do século XXI provocando alterações na economia, na política, na cultura e em todos os aspectos da vida social. Nos países capitalistas essas mudanças contribuem para a manutenção e perpetuação da sociedade burguesa. Trata-se de uma estrutura de controle totalizante e poderosa, na qual os seres humanos, indiscriminadamente, devem ajustar-se para sobreviver. 0 capital não é apenas uma "entidade material", mas uma configuração irrefreável de "controle sociometabólico" que controla tudo e todos objetivando provar a "viabilidade produtiva" do sistema (MÉSZÁROS, 2002, p. 139-140).

Para isso, fazem-se necessários os fundamentos teóricos que sustentam a manutenção da ordem social estabelecida e contribuem para o desenvolvimento de metodologias que regulam não apenas a vida dos indivíduos, mas sobretudo, o trabalho, como demostraremos em relação ao trabalho docente.

A cultura da Ford Company introduziu no início do século XX uma nova disciplina do trabalhador pautada nos Princípios da Administração Científica de Taylor que separava a produtividade do trabalho entre gerência, concepção, controle e execução no processo de trabalho na indústria, criando assim a hierarquia no processo de produção. Mas, a crise do sistema capitalista de 1929 contribuiu para a viabilidade da teoria de John Maynard Keynes, cuja base era determinar um "conjunto de estratégias administrativas científicas e poderes estatais que estabilizassem o capitalismo" (HARVEY, 2005, p. 124). Assim, o Estado tornou-se forte para manter e reproduzir o sistema capitalista, por meio do Estado de Bem-estar Social. Mas o kenezianismo começou a desmoronar fortalecendo as teoria neoliberais a partir dos anos de 1970.

Surge como opção o toyotismo, que flexibiliza o modelo rígido anteriormente colocado e se sustenta na dinâmica de gestão do processo produtivo e no novo padrão tecnológico, cujo conceito base é a flexibilidade. A inovação técnica e organizacional somada ao acréscimo da microeletrônica ao processo produtivo contribuiu para as alterações no processo de trabalho exigindo que os trabalhadores passassem de especialistas qualificados a trabalhadores polivalentes (RODRIGUES, 1998; ANTUNES, 2003) que contribuiu para o surgimento de um trabalhador de novo tipo, mais "qualificado, participativo, 
multifuncional, polivalente" (ANTUNES, 2003, p. 48) e, sobretudo, capaz de maior produtividade no espaço de trabalho.

Pode-se dizer que se o fordismo foi influenciado pelas teorias da Modernidade, o toyotismo foi influenciado pelas da Pós-Modernidade (HARVEY, 2005), cujas teses defendem o fim da centralidade do trabalho e a valorização da "sociedade da informação". Os principais fundamentos teóricos foram desenvolvidos por Peter Drucker, que defende que a "sociedade pós-capitalista" ou "capitalismo informacional" supõe a passagem para a "sociedade do conhecimento" (DRUCKER, 1994). O principal recurso será o conhecimento que ocasionará grupos sociais mais importantes constituídos pelos "trabalhadores do conhecimento", que deverão dominar as TIC viando o aumentando da produtividade.

É necessário garantir que pessoas tomem decisões e se responsabilizem "pela missão da organização, pelo seu espírito, seu desempenho e seus resultados" (DRUCKER, 1995, 54). Esse trabalhador deve praticar todas as suas capacidades intelectivas no desenvolvimento do seu trabalho, em prol da organização. As organizações da "sociedade do conhecimento" devem pautar-se, ainda, na responsabilidade social e individual que requer que cada indivíduo se responsabilize pelos objetivos a serem alcançados pela organização.

São essas as bases teóricas do gerencialismo, que apresenta a "Nova Gestão Pública" como caminho viável para modernização do serviço público e desta forma garantir maior eficiência do Estado articuladas ao livre comércio e ao neoliberalismo mediado pela Terceira Via ${ }^{3}$ (SOUZA, 2015a). No Brasil, o resultado foi a contrarreforma 4 do Estado concretizada no governo de Fernando Henrique Cardoso, por meio da Reforma Administrativa do Aparelho do Estado de 1995 (BRASIL, 1995), que culminou na contrarreforma administrativa, conhecida como "reforma gerencial" para tornar o Estado mais eficiente. Dentro desta lógica, foram definidos alguns elementos da "reforma" dos quais destacamos a promoção da accountability ou a política de responsabilização.

\footnotetext{
3 Como Souza (2015b), usaremos a nomenclatura "neoliberalismo mediado pela Terceira Via" por compreendermos que ela surge das formulações de Giddens quando define que: "É uma terceira via no sentido de que é uma tentativa de transcender tanto a social-democracia do velho estilo quanto o neoliberalismo" (GIDDENS, 1999, p. 36 - grifos nosso).

${ }^{4}$ Para Fernandes (2006), a burguesia implementa a contrarrevolução burguesa e contrarreforma para manter o status quo que impede a verdadeira revolução. Hoje, isso significa que o Estado brasileiro tem optado por garantir os interesses da burguesia em detrimento dos interesses dos trabalhadores por meio da eliminação das políticas sociais.
} 
O princípio de accountability (responsabilização) ou de controle se baseia na "responsabilização por resultados, na competição administrativa por excelência, na responsabilização social e na auditoria de resultados" (BRESSER-PEREIRA, 2008, p. 31). Pode ser "também uma forma de controle, [...] de exercício do poder, mas é uma forma que envolve o próprio controlado na medida em que o torna responsável perante o superior hierárquico e, mais amplamente, perante a sociedade" (BRESSER-PEREIRA, 2008, p. 31). Trata-se de um viés políticoideológico onde $o$

[...] o significado do vocábulo accountability indica frequentemente uma forma hierárquico-burocrática ou tecnocrática e gerencialista de prestação de contas que, pelo menos implicitamente, contem e da ênfase a consequências ou imputações negativas e estigmatizantes, as quais, não raras vezes, consubstanciam formas autoritárias de responsabilização das instituições, organizações e indivíduos (AFONSO, 2012, p. 472 - grifos do autor).

$\mathrm{Na}$ área educacional, a accountability transformou-se em ferramenta eficaz para avaliar e controlar o trabalhador docente já que pode ser concebido como ferramenta para ajudar a solucionar problemas educacionais, contribuindo para a promoção da "qualidade" na educação (MACEDO, 2017a). Tal princípio possibilitou a implementação de novos fundamentos metodológicos para garantir a eficácia do trabalho docente mediante pressupostos gerencialistas.

Um primeiro elemento é que o docente de novo tipo deve dominar as TIC, indispensáveis à "sociedade do conhecimento" (DELORS, 2001). Ele deve dominar e trabalhar com as TIC para promover o desempenho dos estudantes por meio da capacidade de "aprender a aprender", tendo em vista que a aprendizagem deverá ser medida pela avaliação. Na educação básica e também no ensino superior a "docência é entendida como transmissão rápida de conhecimentos, consignados em manuais de fácil leitura para os estudantes, de preferência, ricos em ilustrações e com duplicatas em Cd's [sic]" (CHAUÍ, 1999, p. 5).

Se a aprendizagem ao longo da vida tem sido colocada como necessidade do indivíduo na "sociedade do conhecimento", está em voga a Teoria do Capital Intelectual que não substitui plenamente a Teoria do Capital Humano, mas que super valoriza o conhecimento tácito do trabalhador, segundo elemento a ser destacado. Assim, torna-se possível

[...] objetivar, expropriar e controlar o "conhecimento tácito", que [...] define-se como "[...] altamente pessoal e difícil de formalizar, tornando árdua a tarefa de comunicar ou partilhar com outros". [...] Compõe-se por perspectivas subjetivas, intuições, e palpites, [...] está profundamente enraizado nas ações e experiências de um indivíduo, bem como nos ideais, valores ou emoções que ela abraça (SANTOS, 2009, p. 7). 
Fidalgo conclui: "Tácito designa o conhecimento implícito e informal, que se encontra subentendido por várias pessoas, delas recebendo aprovação" (FIDALGO, 1999, p. 64). É resultante da experiência, da história individual ou coletiva dos indivíduos. Atualmente as empresas e as escolas decodificam e se apropriam desse conhecimento visando enfraquecer os trabalhadores nas relações de trabalho. No caso dos trabalhadores docentes, eles têm sido motivados a serem gestores da sua prática com eficiência, eficácia e produtividade.

Para dominar as TIC e por em prática seus conhecimentos tácitos, o trabalhador docente necessita ter competências, terceiro elemento a ser destacado. Se o chão da empresa ou da escola são os locais de execução do conhecimento tácito, passam a ser também, locais de materialização das competências. As mudanças na produção vão exigir do trabalhador docente novas competências para ensinar, como sendo uma condição básica de enfrentamento da "crescente heterogeneidade dos efetivos escolares e da evolução dos programas" (PERRENOUD, 2000: p. 14). A competência é uma noção que se estabelece como uma nova mediação ou como uma mediação restaurada pela acumulação flexível do capital (RAMOS, 2001) que atende plenamente aos interesses do capital e que passa a ser um conceito de qualificação produtivista, assim como defende Perrenoud (2000). Segundo Ramos (2001), a noção de competência, na contemporaneidade, atende dentre outras coisas a necessidade de "institucionalizar novas formas de educar/formar os trabalhadores e de gerir o trabalho internamente às organizações e no mercado de trabalho em geral, sob novos códigos profissionais em que figuram as relações contratuais, de carreira e de salário" (RAMOS, 2001, p. 39).

Por fim, um último elemento que necessita ser melhor pesquisado para compreendermos seu impacto no trabalho docente é o "reconhecimento do notório saber" que atrelado aos fundamentos teóricos descritos anteriormente enquadra-se perfeitamente aos princípios gerencialitas de Drucker (1995) quando afirma que a aquisição de conhecimento é responsabilidade do indivíduo e a renda está relacionada a um "diploma formal" que passa a ser a certificação do conhecimento adquirido. Vê-se, então, que a lógica do "reconhecimento do notório saber" para realização do trabalho docente na educação básica guarda em si a ideia de educação ao longo da vida, da valorização do conhecimento tácito e das competências estando, portanto, em pleno acordo com a "sociedade do conhecimento".

\section{Precarização, alienação e desprofissionalização do trabalho docente}


As políticas educacionais, produzidas desde os anos 1990, orientadas por princípios do neoliberalismo mediado pela Terceira Via, imprimiram novas características ao trabalho em geral, em toda a sociedade, e também no interior da escola. Para Oliveira (2004), há mudanças significativas na organização e na gestão da educação pública no Brasil, como em outros países latino-americanos, orientados pelos organismos multilaterais. A Conferência Mundial sobre Educação para Todos, realizada em Jomtien, em março de 1990, é um marco nesse sentido, orientando as estratégias de elevação do atendimento escolar às populações dos países periféricos e mais populosos, sem aumentar nas mesmas proporções, contudo, os investimentos. 0 acesso à educação é considerado um fator de redução das desigualdades.

Passa a ser um imperativo dos sistemas escolares formarem os indivíduos para a empregabilidade, já que a educaşão geral é tomada como requisito indispensável ao emprego formal e regulamentado, ao mesmo tempo em que deveria desempenhar papel preponderante na condução de políticas sociais de cunho compensatório, que visem à contenção da pobreza (OLIVEIRA, 2004, p. 1129, grifos nossos).

Nesse sentido, as políticas que passam a ser elaboradas obedecem a determinadas orientações que se encaixam no reduzido papel do Estado na elaboração de políticas sociais que atendam toda a população. No caso das políticas educacionais, Oliveira (2004) destaca: a centralidade da administração escolar, assinalando a escola como núcleo da gestão; o financiamento per capita com a criação do Fundo de Manutenção e Desenvolvimento do Ensino Fundamental e de Valorização do Magistério (Fundef), posteriormente, ampliado para Fundo de Manutenção e Desenvolvimento da Educação Básica e de Valorização dos Profissionais da Educação toda a Educação Básica (Fundeb); a instalação de um sistema de avaliação pelo Estado que passa a assumir o papel de controlador5; avaliação institucional; e, a gestão democrática, associada à descentralização, de modo que as escolas busquem realizar arranjos locais para sua complementação orçamentária na comunidade ou por meio de em diversas parcerias por elas realizadas.

Do ponto de vista do trabalho em geral, os conceitos de produtividade, eficácia e eficiência, quando incorporados à produção material imprimiram-lhe novas características, a partir da chamada reestruturação produtiva, podendo-se citar, entre outras coisas: a desregulamentação do trabalho com redução dos

\footnotetext{
${ }^{5}$ Com base no gerencialismo educacional instalou-se um novo tipo de controle por meio de um sistema complexo de avaliação de todos os níveis de ensino. Para isso foram criados: o Sistema de Avaliação da Educação Básica (Saeb), instituído em 1990; o Exame Nacional do Ensino Médio (ENEM), criado em 1998; e, o Exame Nacional de Desempenho dos Estudantes (ENADE), criado em 2004.
} 
trabalhadores estáveis e dos empregos formais; aumento do trabalho feminino precarizado; a exclusão de jovens e dos trabalhadores mais velhos; expansão do terceiro setor; a transnacionalização do capital e do trabalho (ANTUNES; ALVES, 2004). Ao incorporar esses conceitos característicos do campo econômico das teorias administrativas, visando baixar custos e permitir o controle central das políticas implantadas, novas alterações são impostas às escolas públicas em seus aspectos estruturais e organizacionais assentados nestes mesmos conceitos (produtividade, eficácia e eficiência) que vão alterar também a forma como o trabalho docente se realiza repercutindo fortemente no aumento de sua precarização e na sua intensificação.

Neste sentido, a ideia de precarização do trabalho docente pode ser compreendida a partir das mudanças oriundas da "Nova Gestão Pública" ou "Gerencialismo" que afetaram as condições do trabalho docente, com diversas repercussões sobre esses trabalhadores. De modo especial, a precarização reforça uma ideia de subjugação dos trabalhadores em educação às necessidades de competitividade e produtividade, que pode ser traduzida como perda de autonomia, desqualificação e até desprofissionalização, ao estabelecer padrões de atuação aos docentes segundo critérios que não mais dizem respeito à sua natureza, mas que passam a responder, quase exclusivamente, a critérios de mercado. Além disso, a precarização do trabalho docente se materializa, também: 1) pela terceirização, sob diferentes formas entre as quais a subcontratação de empresas de prestação de serviços educacionais ou de contratação de cooperativas de trabalho e/ou de pessoa jurídica ou autônoma; 2) pela individualização das relações e da organização do trabalho; 3) pela gestão de competências e de avaliação de performances, com incidência sobre a remuneração do trabalho, sob a forma de bônus ou prêmios diferenciados, segundo critérios baseados na lógica produtivista (SOUZA 2011).

Outro sentido da precarização do trabalho docente pode ser tomado pelos processos que resultam na sua intensificação. 0 termo deriva da noção inicial de intensidade do trabalho, referindo-se a "quando os resultados são quantitativa ou qualitativamente superiores, razão pela qual se exige um consumo maior de energias do trabalhador (DAL ROSSO, 2008, p. 21). Quando o trabalho é de tipo intelectual, a melhoria nos resultados é qualitativa. Referem-se à intensificação, "os processos de quaisquer naturezas que resultam em maior dispêndio das capacidades físicas, cognitivas e emotivas do trabalhador com o objetivo de elevar quantitativamente ou melhorar qualitativamente os resultados. Em síntese, mais trabalho" (DAL ROSSO 2008, p. 23). 
Alguns aspectos têm adquirido relevância na materialização destas políticas no cotidiano das escolas e da forma como são colocadas em prática estratégias que vêm alterando as formas pelas quais se organiza o trabalho docente e até mesmo a natureza deste trabalho. Destacam-se a centralidade dos professores na responsabilização pelo sucesso e pelo fracasso dos alunos, da escola e do sistema, a partir das avaliações implantadas e conduzidas pelos órgãos centrais, associadas a um sistema de bonificação que ranqueia as escolas, e cria situações de adversidade entre os professores que são considerados individualmente na avaliação da instituição, embora essa seja premiada coletivamente. A adoção deste mecanismo apoia-se na ideia de accountability, isto é, na responsabilidade social, na obrigatoriedade da prestação de contas à população, com a mensuração dos resultados do serviço prestado a partir de critérios estabelecidos a priori.

Conjugada a esta ideia os trabalhadores docentes assumem diferentes funções dentro da escola para enfrentar as exigências burocráticas impostas pelos órgãos centrais - que vem, ao longo do tempo, colocando em prática formas de controle do trabalho docente, especialmente, por meio das TIC - e a falta de pessoal administrativo para diferentes setores, diretamente ligado à função docente, interferindo na qualidade de seu trabalho. No entanto, nota-se que as instâncias de decisão e de poder permanecem bastante separadas na escola, nas quais há reduzida participação docente nestes processos (MELLO, 2013).

Deste modo, o aumento das funções exercidas pelos docentes no interior das escolas, a distribuição da carga horária que estende o tempo de permanência dos docentes com os estudantes, mas não reserva tempo para estudo, para o planejamento individual e coletivo, para preparação e correção de materiais e, a falta de pessoal administrativo e de suporte pedagógico conjugam-se como aspectos de uma mesma estratégia de intensificação do trabalho docente. Os docentes passam a trabalhar mais no mesmo tempo de que dispunham antes, e até mesmo, estendendo sua jornada de trabalho para fora da escola, comprometendo muitas vezes seu tempo que deveria ser usado para o descanso e o lazer. Intensificação que ao conjugar o aumento do controle e a falta de condições do exercício da função docente autonomamente, aliena-o em seu processo de trabalho contribuindo decisivamente para o aprofundamento dos processos de desprofissionalização docente.

Outro aspecto refere-se ao apelo ao voluntariado e às organizações sociais, contribuindo para instalar uma situação de desvalorização dos docentes que, muitas vezes, são substituídos por pessoas sem formação para realizar aquilo que seria de sua alçada, sem que sejam chamados para participar desse processo. 
Alguns desses voluntários chegam a ser melhor remunerados que os próprios docentes concursados e efetivados nas escolas municipais e estaduais, que chegam receber salários de menor valor ${ }^{6}$. A ênfase na terceirização e no contrato temporário de trabalho, bem como a terceirização, por meio de contratação de empresas privadas ou por meio de parcerias público-privadas entre o Estado e organizações sociais ou instituições filantrópicas, encontra-se entre os mecanismos de precarização do trabalho docente.

Evidencia-se, também, que as condições de trabalho não permitem a elaboração de um Projeto Político Pedagógico (PPP) que seja resultado do trabalho coletivo e organizado para fazer frente às determinações externas o que contribui para a fragmentação do trabalho pedagógico, muitas vezes, resultado mais da desarticulação do trabalho coletivo do que da adoção da ideia de uma pluralidade na orientação teórico-metodológica do trabalho docente. 0 trabalho torna-se personalizado, individualizado, excluindo qualquer possibilidade de realização do trabalho coletivo.

Ressalta-se aqui a discussão feita por Linhart (2007) acerca da instalação das práticas de individualização como resultado de uma política para motivar as pessoas que passam a se orientar por valores individuais. Trabalham com outras pessoas em coletivos apenas em determinados momentos e com determinadas necessidades, ou seja, em coletivos operacionais. Assim, se destrói os valores de uma cultura de trabalho em grupo e do sentimento de classe ao mesmo tempo em que desmobiliza os coletivos necessários ao enfrentamento dos problemas e a criação das formas para sua superação. Estratégia própria da "Nova Gestão Pública" que valoriza a individualização das pessoas e das relações de trabalho.

Pensando ainda, no contexto operado pela contrarreforma do Estado brasileiro, a descentralização é uma das características que pode ser destacada na política educacional do país nos últimos anos, enfatizando-se a transferência de recursos que se refere também à transferência de responsabilidades em torno da gestão da escola, reduzindo desta forma, o papel do Estado e pondo ênfase na sua função de controle.

Essas políticas reforçam a descrição dos docentes sobre o cotidiano de seu trabalho que, de maneira geral, revela que este continua sendo realizado num

\footnotetext{
${ }^{6}$ Como exemplo disto, o reforço escolar está organizado nas escolas municipais do Rio de Janeiro, por meio da realização de oficinas em diversas modalidades (esportes, arte plástica, música, capoeira, Matemática, Português etc.) oferecidas por "oficineiros" escolhidos na comunidade e financiados pela escola por meio do Programa Mais Educaşão e, no caso dos anos finais, também pelo Projeto Ensina (MELLO, 2013).
} 
contexto de separação entre a concepção e execução do trabalho - neste caso materializado de modo mais determinante nas relações entre as secretarias de educação e os docentes da escola - cabendo a quem concebe o monopólio do conhecimento para controlar cada fase do processo de trabalho e seu modo de execução, assim como a avaliação do trabalho realizado (MELLO, 2013). Separação essa, cujas raízes encontram-se no taylorismo da modernidade e que se reorganiza no toyotismo da pós-modernidade com suas marcas do gerencialismo que refletem nas as políticas educacionais adotadas, com vistas a atender as novas exigências da "sociedade do conhecimento", cujo resultado tem sido a perda da autonomia sobre o próprio trabalho operando, assim, uma desqualificação progressiva que pode representar um tipo de desprofissionalização. É o caso, por exemplo, da adoção de estratégias do "reconhecimento notório saber" (MACEDO, 2017b), o que na prática, significa que o sistema educacional passa a aceitar como "qualificação" profissional para a realização do trabalho docente apenas a especialização técnica de alguma área específica do conhecimento, tornando dispensável qualquer discussão em torno da profissão que exige uma formação própria e profunda, levando a uma degradação social da profissão.

Observa-se uma divisão do trabalho - separação entre concepção e execução - também em relação às definições acerca da gestão, da organização do trabalho, mas de modo mais evidente, em relação à elaboração do currículo, da avaliação e, até mesmo, da metodologia. Pode-se observar, pois, o que Braverman (1987) denomina de princípio da dissociação do processo de trabalho das especialidades dos trabalhadores, em que, uma vez realizada, passa a não mais depender da capacidade dos docentes, mas inteiramente da política gerencial.

A ênfase na descentralização dos recursos, na avaliação centralizada, na adoção de políticas que visam aprimorar mecanismos da "gestão" e priorizar os investimentos em infraestrutura, a falta de pessoal e de investimentos em formação apontam a orientação política de caráter gerencialista. Dentro dessa lógica, a prioridade é dada a diminuição dos gastos nas escolas públicas por meio da correção de fluxo e da implantação de mecanismos de gestão baseados nas avaliações externas vinculadas a um sistema de bonificação. Passa-se a entender qualidade como produtividade, com eixo na eficiência e eficácia; a terceirização, com a introdução de novos setores públicos não-estatais, "não-governamentais"; e, a privatização, por meio da aquisição de programas e materiais didáticopedagógicos. Tais iniciativas precarizam o trabalho docente, corroem sua 
autonomia e acarretam um contínuo processo de desprofissionalização e desvalorização docente.

Nesse contexto, as políticas de formação para o trabalho docente necessitam se ajustar de modo a refletir os interesses do capital para a formação do docente de novo tipo, capaz de formar indivíduos também de novo tipo, totalmente moldados à lógica da "sociedade do conhecimento".

\section{Precarização na formação para o trabalho docente}

Em consonância com o relatório da UNESCO de 1996 (DELORS, 2001) e com o Compromisso de Dakar de 2000 (UNESCO, 2001) sobre educação para o século XXI, a concepção de "educação ao longo da vida" vai se materializando tendo em vista a ideia de uma sociedade articulada em prol da paz, da harmonia, da solidariedade, da democracia e da justiça social.

Neste sentido, a formação para o trabalho docente em nível superior se constitui em uma estratégia que contribua com a elevação da "qualidade" da educação básica e do desempenho do sistema educacional, passando ser uma exigência que responda à complexidade do trabalho docente na "sociedade do conhecimento" fundamentada na lógica da "educação ao longo da vida", que deve ser por meio da formação inicial e continuada. A UNESCO, o BM e a OCDE indicam reduzir os investimentos para essa formação por meio do treinamento em serviço (saber fazer, saber usar, saber gerir etc.) e da Educação a Distância (EaD), compondo dessa forma, o consenso em torno da formação do docente de novo tipo, por meio da "pedagogia política" (SOUZA, 2015a e 2015b).

Desde 1966 a UNESCO defende a formação docente em nível superior por meio de um programa de formação amplo, para o desenvolvimento de conhecimentos gerais e cultura pessoal; de aptidão para ensinar e educar; que compreenda os princípios fundamentais para o estabelecimento de boas relações humanas dentro e fora das fronteiras nacionais; que tenha consciência do dever de contribuir com a melhoria da qualidade do ensino e com o desenvolvimento social, cultural e da sociedade. A formação contínua privilegiava a experiência técnica e profissional por meio das técnicas pedagógicas. A partir de 1996 (DELORS, 2001) foi colocada sob o professor a responsabilidade de "aprender ao longo da vida". Com esta premissa, em Dakar no ano 2000 (UNESCO, 2001), postulou-se pela melhoria do status, autoestima e profissionalização docente tomando por base que

[...] o docente do século XXI deve ser um profissional reflexivo, comprometido com as mudanças, protagonista na elaboração das propostas educacionais e dotado de 
novas competências que lhe dêem a flexibilidade necessária para atender alunos diversos e adaptar-se às novas situações que a sociedade, em permanente transformação lhe propõe (CONSED.UNESCO, 2007, p. 13).

Se em 1966 o indicativo era de que a formação do professor deveria estar sob a responsabilidade do Estado, a partir de 1996 percebe-se uma supervalorização das TIC que passa a ser o principal instrumento para a formação docente, inclusive como recursos para garantir a EaD em nível superior, colocando sobre este trabalhador a responsabilidade de sua formação inicial e continuada.

O documento Prioridades y Estrategias para la Educacion: estudio sectorial del Banco Mundial (1995) do BM, maior financiador da educação, passou a ser referência para o Brasil no que se refere a implementação de políticas educacionais e de formação docente no governo FHC da mesma forma que o documento Brasil Teachers Development and Incentives: a strategic Framework (2001) fundamentou as políticas de formação docente do governo Lula da Silva, principalmente no que se refere à formação em nível superior. Ambos os documentos reafirmam que políticas educacionais promovem o desenvolvimento e a redução da pobreza nos países periféricos, mas a experiência tem mostrado que os elementos principais do "pacote" funcionam mais como controle dos países financiados.

Em 1995 as preocupações referentes à formação docente se pautavam na lógica da formação em serviço como caminho mais viável para a redução de recursos e promoção do aumento de docentes qualificados/capacitados. A partir de 2001 houve mudança de enfoque e a prioridade se volta à formação docente para a educação básica em nível superior colocando o tema da gestão como "carro chefe". A sugestão é que o Brasil necessita "retreinar e certificar os professores em nível superior" (BM, 2001, p. 20) por que há pouca ênfase sobre o trabalho docente colaborativo, na transvesalidade dos currículos, na aproximação da comunidade escolar, da participação efetiva no planejamento e na gestão da escola. Além disso, a formação para dominar as TIC é limitada e o sistema de avaliação da prática docente não é eficaz. É preciso considerar que

[...] há um consenso emergente nos países da Ocde e de muitos países em desenvolvimento nas metas de preparação de professor e produção de um novo tipo de professor, equipados não só com o conhecimento do conteúdo mais profundo e mais flexível, mas também uma melhor compreensão do desenvolvimento da criança e estilos de aprendizagem, um repertório mais amplo de estratégias de ensino e um novo conjunto de valores, enfatizando o respeito à diversidade, a colaboração com os colegas e reflexão contínua sobre a prática docente e uma capacidade de liderar a mudança e comunicar-se eficazmente (BM, 2001, p. 23 - tradução livre). 
A preocupação dos vários países da OCDE está em recrutar professores qualificados que irão substituir os aposentados e garantir a eficácia daqueles que deverão adquirir competências necessárias para acompanhar as mudanças da "sociedade do conhecimento" (OCDE, 2006). Se a escola do século XXI deve ser eficaz, os "professores devem ser capazes de preparar os estudantes para uma sociedade e uma economia em que se espera que sejam aprendizes autodirecionados, capazes e motivados a seguir aprendendo ao longo da vida" (OCDE, 2006, p. 7). A profissão docente precisa ser atraente e, se não implementar mudanças necessárias à "sociedade do conhecimento" cairá os índices de qualidade das escolas. 0 desenvolvimento e implementação de políticas eficazes para professores considera a participação dos professores e seus representantes na formulação de políticas (OCDE, 2006, p. 225), contudo, observamos que isso tem contribuído mais para a produção do consenso (SOUZA, 2015a e 2015b), imposto pela burguesia.

0 professor eficaz necessita de um nível determinado de experiência ligada à sua capacidade de gerenciamento. As políticas de formação para o trabalho docente centrarem-se em "atrair, desenvolver, recrutar e reter" e devem considerar o que os professores sejam capazes de "fazer". As tendências nas políticas de formação docente fortalecem as tendências do ensino superior que são: expansão; diversificação da oferta; conjunto de alunos mais heterogêneos; novos meios de financiamento; foco crescente na responsabilidade e nos resultados; novas formas de governança institucional; implementação de rede mundial, mobilidade e colaboração (OCDE, 2008; 2010).

No complexo da contrarreforma do Estado brasileiro, para ajuste da formação para o trabalho docente na a educação básica às novas exigências da "sociedade do conhecimento" não bastou interferir apenas no lócus de formação, mas, sobretudo, no conteúdo da formação que deve adequar-se às concepções da "Nova Gestão Pública", centrada no desenvolvimento das competências comportamentais.

A Lei 9.3496 colocou como imperativo a necessidade de formação para o trabalho docente em suas múltiplas dimensões (Título VI, artigo 62). 0 artigo 63 destaca que cabe aos institutos superiores de educação promover o aperfeiçoamento profissional e continuado (Inciso III) ao mesmo tempo em que estabeleceu no artigo 61, inciso I, a "associação entre teorias e práticas, inclusive mediante a capacitação em serviço" (Inciso I). Essa Lei adotou as nomenclaturas "formação de profissionais da educação" (artigo 61) e "formação de docentes" 
(artigo 62) para designar o que aqui chamaremos de "formação para o trabalho docente".

No ano de 2002, o Conselho Nacional de Educação (CNE) institui as Diretrizes Curriculares Nacionais para a Formação de Professores da Educação Básica, em nível superior, curso de licenciatura, de graduação plena (BRASIL, 2002), objetivando promover a articulação entre os termos "formação profissional" e/ou o "exercício profissional" ligado à formação.

O Decreto № 6.755/2009 instituiu a Política Nacional de Formação de Profissionais do Magistério da Educação Básica "com a finalidade de organizar, em regime de colaboração entre a União, os Estados, o Distrito Federal e os Municípios, a formação inicial e continuada dos profissionais do magistério para as redes públicas da educação básica" (BRASIL, 2009), destacando a responsabilidade do docente no "processo educativo da escola e de sua valorização profissional," bem como sua "formação continuada" (artigo 2º inciso VIII). No que se refere à formação inicial o Decreto prevê "a eqüidade no acesso à formação inicial e continuada" (inciso IX) e a "articulação entre formação inicial e formação continuada" (inciso X). Em conformidade com as alterações relativas à formação para o trabalho docente ainda no mesmo ano, o Decreto № 12.014/2009 altera o artigo 61 da Lei 9.394/96 para distinguir as categorias destes trabalhadores que devem ser considerados profissionais da educação básica.

De acordo com a Lei 9.394/1996 a exigência para a realização do trabalho docente na educação básica far-se-á mediante a formação em cursos de nível médio (modalidade Normal) ou superior reconhecido. A formação dos demais trabalhadores da educação será feita em cursos de Pedagogia podendo ser reconhecidos, ainda, os títulos obtidos em cursos de Pós-Graduação Stricto Sensu.

A Resolução № 04/2010, que define as Diretrizes Curriculares Nacionais Gerais para a Educação Básica, especifica no capítulo IV, artigo 56, que a fundamentação da ação docente bem como os programas de formação inicial e continuada dos profissionais da educação exige um método de aprendizagem com vistas a formar o perfil do docente da educação básica. Neste aspecto, o $§ 1^{\circ}$ prevê que as instituições formadoras deverão incluir em seus currículos e programas elementos que visem este fim. 0 artigo 57 define que a formação inicial e continuada deve ligar-se aos princípios definidos para a educação nacional incluindo a valorização do profissional da educação com extensão para a valorização da escola com qualidade na gestão, na cultura, etc. Evidencia-se, também a ideia de formação global desse trabalhador, que deverá exercer suas 
atividades segundo exigências do mercado de trabalho. Dele se exige não apenas a atualização, mas sobretudo, a disponibilidade para a elaboração de matérias didáticos, planejamento pedagógico, participação na comunidade escolar etc. (MACEDO, 2017a).

Com essas medidas, a política de formação para o trabalho docente no Brasil atende plenamente às exigências dos organismos internacionais (BM, UNESCO, OCDE) que apontam a necessidade de uma formação prática (savoir-faire) em detrimento da teoria, alegando que a formação feita nas Instituições de Ensino Superior (IES) são custosas e demoradas e que não formam para a realidade das escolas. Além disso, a escola é culpada pelo fracasso do estudante à medida que promove o distanciamento entre os conteúdos ensinados e as novas demandas do mundo do trabalho e da produção. O MEC reforça esse discurso por meio dos seus intelectuais quando afirma que "os professores são despreparados para trabalhar com o aluno da escola pública e que se sentem abandonados e sem assistência para enfrentar tão difícil tarefa, para a qual não receberam formação adequada" (MELLO, 2005, p. 60). Por isso, deverá ser substituído por professores que deverão ser "atraídos" e "recrutados" de outras áreas do conhecimento (OCDE, 2006).

Recentemente surge a possibilidade do "reconhecimento do notório saber" (MACEDO, 2017b) para realização do trabalho na educação básica, que embora reconheçamos se tratar de uma medida para o reconhecimento público de conhecimento e/ou erudição, não pode se constituir em solução para o trabalho docente. Contudo, a Lei № 13.415/2017 - resultada da Medida Provisória № $746 / 2016$ - reconhece no artigo 61, inciso IV, os

[...] profissionais com notório saber reconhecido pelos respectivos sistemas de ensino, para ministrar conteúdos de áreas afins à sua formação ou experiência profissional, atestados por titulação específica ou prática de ensino em unidades educacionais da rede pública ou privada ou das corporações privadas em que tenham atuado [...] (BRASIL, 2017).

No entanto, como a MP № 746/2016, a Lei № 13.415/2017 não prevê as formas de certificação do "reconhecimento do notório saber", mas avança no sentido de indicar as instituições de educação com "notório reconhecimento" que poderão oferecer cursos de nível médio se cumpridas as exigências curriculares deste grau de ensino. De acordo com o $§ 11$ da Lei, os sistemas de ensino "poderão reconhecer competências e firmar convênios com instituições de educação a distância" (BRASIL, 2017). 
Não resta dúvida de que a proposta de Mello (2000), no que se refere à política nacional de formação de professores bem se encaixa nesta lógica de criação do consenso em torno do credenciamento de cursos e certificação de competências. Primeiro, porque a autora defende o rejuvenescimento do Curso Normal de Nível Médio para formar "professor polivalente", segundo porque a formação para o trabalho docente, nestes espaços, poderá ser feita de modo aligeirado com auxílio das TIC.

O excessivo número de regulamentação da formação para o trabalho docente no Brasil a partir dos anos de 1990 estão de acordo com a lógica da "Nova Gestão Pública" por valorizar a ideia de accountability, da formação ao longo da vida, do conhecimento tácito, das competências e, mais recentemente do "reconhecimento do notório saber" provocando o aligeiramento e a fragmentação da formação garantindo, dessa forma, a manutenção e perpetuação da sociedade burguesa sob influência da "sociedade do conhecimento".

\section{Conclusão}

Diante das significativas mudanças econômicas, políticas, culturais e sociais pelas quais passa o mundo neste século XXI, torna-se necessário compreender esta realidade de forma mais abrangente e totalizante, de modo a buscar os diversos elementos que se conjugam numa estrutura poderosa de produção e manutenção do capitalismo contemporâneo. Neste sentido, a educação, de modo especial, a educação escolar, passa a ser parte significativa dos processos de produção e reprodução da ordem vigente.

Como nos chama atenção Mészáros "poucos negariam hoje que os processos educacionais e os processos sociais mais abrangentes de reprodução estão intimamente ligados" (2005, p. 25). Deste modo, é inconcebível pensar processos de transformação da educação sem as transformações correspondentes na realidade social, correndo-se o risco de, sob tal limitação, realizarem-se apenas reformas ou ajustes na ordem estabelecida mantendo inalterada a lógica deste sistema de reprodução (MÉSZÁROS, 2005).

Deste modo, para compreendermos o trabalho docente nas sociedades capitalistas contemporâneas necessitamos analisar os fundamentos teóricos que sustentam a ordem estabelecida, que organizam e sustentam o trabalho em geral, bem como os fundamentos e as metodologias que regulam a vida social.

Neste sentido, encontram-se nas bases da reestruturação produtiva realizada ao longo do século XX e neste início do século XXI, as bases da reorganização do trabalho docente em correspondência com as mudanças impostas à organização 
e ao gerenciamento do trabalho em geral. As políticas educacionais produzidas desde os anos 1990 no Brasil, assentadas nos princípios do gerencialismo, imprimiram novas características à organização da gestão da escola e do trabalho docente, a partir dos conceitos de produtividade, eficácia e eficiência, repercutindo em sua intensificação e precarização, em muitos casos, resultando em processos de desprofissionalização dos trabalhadores docentes por meio da perda da autonomia sobre o processo de trabalho e da desqualificação profissional. Neste sentido, que dois processos destacam-se na análise dos fundamentos da precarização do trabalho docente na contemporaneidade: a organização e gestão deste trabalho e a formação dos trabalhadores docentes.

Como consequência, as mudanças na formação docente, passam a estar em consonância com a formação do trabalhador de novo tipo, necessário aos processos de reestruturação do capital em seu atual estágio de acumulação. Passa-se a desenvolver no processo de formação docente, as mesmas "competências" a serem exigidas da formação a ser desenvolvida pela educação em geral, pela escola e pelos docentes. Os processos de diversificação das instituições formadoras indicam as mudanças ocorridas no lócus de formação, mas pode-se apontar como mais relevante, as mudanças empreendidas no conteúdo desta formação que enfatizam a necessidade do desenvolvimento de competências em consonância com as exigências da "sociedade do conhecimento", tendo em vista a formação do trabalhador de novo tipo. Neste contexto, os docentes possuem papel fundamental na construção do consenso social como estratégia para o desenvolvimento do capital.

A nova organização do trabalho na escola e os novos modelos de formação docente impõem novos desafios e questões a serem enfrentadas do ponto de vista político, tanto no que diz respeito à formação, às condições de trabalho como à própria natureza do trabalho docente e às formas de sua realização nos contextos de trabalho organizados com base na lógica da "Nova Gestão Pública".

Faz-se necessário, nesse sentido, fortalecer a ideia da educação superior, colocando a universidade como o lócus privilegiado da formação para o trabalho docente na educação básica, capaz de contribuir para a emancipação humana e para a construção de outra sociabilidade que não a capitalista. Dentro desses pressupostos, as políticas de formação para o trabalho docente e as formas nas quais este trabalho se organiza e se desenvolve exigem uma análise profunda dos seus fundamentos teóricos e metodológicos para compreensão e elaboração de novas estratégias transformadoras. 


\section{Referências Bibliográficas}

AFONSO, Almerindo Janela. Para uma concetualização alternativa de accountability em educação. Educação e Sociedade, Campinas (SP), v. 33, n. 119, p. 471-484, abr./jun. 2012.

ANTUNES, Ricardo. Os sentidos do trabalho: ensaio sobre a afirmação e a negação do trabalho. 6. ed. São Paulo: Boitempo, 2003.

; ALVES, Giovanni. As mutações no mundo do trabalho na Era da mundialização do capital. Educação e Sociedade, Campinas, v, 25, n. 87, p. 299302, mai/ago. 2004.

BANCO MUNDIAL. Brazil Teachers Development and Incentives: a strategic framework. 2001. Disponível em: <http://siteresources.worldbank.org/ BRAZILINPOREXTN/ Resources/3817166-185895645304/4044168118632690260 7/41pub_br62.pdf>. Acesso em: 12/08/2010.

Prioridades y Estratégias para a la Educacion: estúdio sectorial del Banco Mundial (Version preliminar). Washington (EUA), mayo 1995. Mimeografado.

BRASIL. Decreto № 6.755, de 29 de janeiro de 2009. 2009. Institui a Política Nacional de Formação de Profissionais do Magistério da Educação Básica, disciplina a atuação da Coordenação de Aperfeiçoamento de Pessoal de Nível Superior -CAPES no fomento a programas de formação inicial e continuada, e dá outras providências. Publicado no DOU de 30.01.2009. Disponível em: $<$ http://www.planalto.gov.br/ ccivil_03/_Ato2007-2010/ 2009/Decreto/D6755.htm>. Acesso em: 25/02/2010.

Lei № 12.014, de 6 de agosto de 2009. 2009. Altera o art. 61 da Lei no 9.394, de 20 de dezembro de 1996, com a finalidade de discriminar as categorias de trabalhadores que se devem considerar profissionais da educação. Disponível em: <https://www.planalto.gov.br/ccivil_03/_Ato20072010/2009/Lei/L12014.htm>. Acesso em: 22/10/2009.

. Lei № 13.415, de 16 de fevereiro de 2017. Altera as Leis nos 9.394, de 20 de dezembro de 1996, que estabelece as diretrizes e bases da educação nacional, e 11.494, de 20 de junho 2007, que regulamenta o Fundo de Manutenção e Desenvolvimento da Educação Básica e de Valorização dos Profissionais da 
Educação, a Consolidação das Leis do Trabalho - CLT, aprovada pelo Decreto-Lei no 5.452, de 1 o de maio de 1943, e o Decreto-Lei no 236, de 28 de fevereiro de 1967; revoga a Lei no 11.161, de 5 de agosto de 2005; e institui a Política de Fomento à Implementação de Escolas de Ensino Médio em Tempo Integral. Disponível em: < http://www.planalto.gov.br/ccivil_03/_Ato2015-2018/2017/ Lei/L13415. htm>. Acesso em: 12/03/2017.

. Lei № 9394, de 20 de dezembro de 1996. Lei de Diretrizes e Bases da Educação Nacional. Brasília, 1996.

BRASIL. Medida Provisória № 746, de 22 de setembro de 2016. Institui a Política de Fomento à Implementação de Escolas de Ensino Médio em Tempo Integral, altera a Lei no 9.394, de 20 de dezembro de 1996, que estabelece as diretrizes e bases da educação nacional, e a Lei no 11.494 de 20 de junho 2007, que regulamenta o Fundo de Manutenção e Desenvolvimento da Educação Básica e de Valorização dos Profissionais da Educação, e dá outras providências. Disponível em: <https://www.planalto.gov.br/ccivil_03/_Ato20152018/2016/Mpv/mpv746.htm>. Acesso em: 12/03/2017.

Plano Diretor da Reforma do Aparelho do Estado. Brasília: Câmara da Reforma do Estado, 1995. Disponível em: <http://www. bresserpereira. org.br/documents/mare/planodiretor/planodiretor.pdf $>$. Acesso em: $13 / 05 / 2015$.

BRASIL. Resolução CNE/CP 1, de 18 de fevereiro de 2002. 2002. Institui Diretrizes Curriculares Nacionais para a Formação de Professores da Educação Básica, em nível superior, curso de licenciatura, de graduação plena. Brasília (DF), 2002.

Resolução № 4, de 13 de julho de 2010. 2010. Define Diretrizes Curriculares Nacionais Gerais para a Educação Básica. Disponível em: <http://portal.mec.gov.br/dmdocuments/rceb004_10.pdf>. Acesso em: 21/08/2010.

BRAVERMAN, Harry. Trabalho e capital monopolista: a degradação do trabalho no século XX. Tradução: Nathanael C. Caixeiro. Rio de Janeiro: LTC, 1987.

BRESSER-PEREIRA, Luiz Carlos. Os primeiros passos da reforma gerencial do Estado de 1995. Trabalho escrito para ser publicado em livro organizado por Maria Ângela d'Incao. 2008. Disponível em: <http://www.resserpereira. 
org.br/papers /2008/08.13.Primeiros.PassosReformaGerencial.pdf>. Acesso em: 06/01/2009.

CHAUÍ, Marilena. A universidade operacional. Folha de São Paulo. Caderno Mais! 9 de maio de 1999. Disponível em: <http://reuniufpr.forumativo.com/documentos-f1/a-universidade-operacionalmarilena-chaui-t46.htm>. Acesso em: 20/01/2010.

CONSELHO NACIONAL DE SECRETÁRIOS DE EDUCAÇÃO (CONSED). UNESCO. 0 desafio da profissionalização docente no Brasil e na América Latina. Brasília: CONSED, UNESCO, 2007.

DAL ROSSO, Sadi. Mais trabalho!: a intensificação do labor na sociedade contemporânea. São Paulo: Boitempo, 2008.

DELORS, Jacques (Org.). Educação: um tesouro a descobrir - Relatório da Unesco da Comissão Internacional sobre Educação para o Século XXI (1996). 6.ed.. São Paulo: Cortez; Brasília: MEC: Unesco, 2001.

DRUCKER, Peter. A sociedade pós-capitalista. Tradução de Nivaldo Montingelli Júnior. 2. ed. São Paulo: Pioneira, 1994.

Administrando em tempos de grandes mudanças. Tradução de Nivaldo Montigelli Júnior. São Paulo: Pioneira, 1995.

EVANGELISTA, Olinda; SHIROMA, Eneida Oto. Professor: protagonista e obstáculo da reforma. Educação e Pesquisa, São Paulo, v. 33, n.3, p. 531-41, set/dez. 2007.

FERNANDES, Florestan. A revolução burguesa no Brasil: ensaio de interpretação sociológica. 5.ed. São Paulo: Globo, 2006.

FIDALGO, FIDALGO, Fernando Selmar. A formação profissional negociada: França e Brasil, anos 90. São Paulo: A. Garibaldi, 1999.

FRIEDMAN, Milton. Capitalismo e liberdade. Tradução de Luciana Carli. Rio de Janeiro: Editora Artenova, 1977.

GIDDENS, Anthony. A terceira via: reflexões sobre o impasse político atual e o futuro da social-democracia. Tradução de Maria Luiza X. de A. Borges. $2^{\text {a }}$ tiragem. Rio de Janeiro: Record, 1999. 
HARVEY, David. Condição pós-moderna. 14. ed. Tradução de Adail Ubirajara Sobral e Maria Stela Gonçalves. São Paulo: Loyola, 2005.

HAYEK, Friedrich August Von. 0 caminho da servidão. Rio de Janeiro: Biblioteca do Exército, 1994.

KOSIK, Karel. Dialética do concreto. Tradução de Célia Neves e Alderico Toríbio. Rio de Janeiro: Paz e Terra, 1969.

LINHART, Danièle. A desmedida do capital. Tradução: Wanda Caldeira Brant. São Paulo: Boitempo, 2007.

MACEDO, Jussara Marques de. Notório saber e a negação da educação superior como lócus de formação para o trabalho docente na educação básica. In: XXV Seminário Nacional Universitas, Brasília (DF), 17 a 19 de maio de 2017. Anais. Brasília (DF): Miroservice, 2017b. CD Rom. 18p.

Formação para o trabalho docente. Curitiba: Appris, 2017a.

MELLO, Guiomar Namo de. Cidadania e competitividade: desafios educacionais do terceiro milênio. 10. ed. São Paulo: Cortez, 2005.

Formação inicial de professores para a educação básica: uma (re)visão radical. São Paulo em Perspectiva, São Paulo, vol. 14, n. 1, p. 98-110, jan./mar., 2000.

MELLO, Míriam Morelli Lima de. A escola como espaço de transformação social: professores, trabalho e hegemonia. 2013. Tese (Doutorado em Educação) - Programa de Pós-Graduação em Educação, Universidade Estadual de Campinas, Campinas, 2013.

MÉSZÁROS, István. Para além do capital. Tradução de Paulo César Castanheira e Sérgio Lessa. São Paulo: Boitempo; Campinas (SP): Editora da UNICAMP, 2002.

OLIVEIRA, Dalila Andrade de. A reestruturação do trabalho docente: precarização e flexibilização. Educação e Sociedade, Campinas, v. 25, n. 89, p. 1127-1144, set/dez. 2004.

ORGANIZAÇÃO DAS NAÇÕES UNIDAS PARA A EDUCAÇÃO, A CIÊNCIA E A CULTURA (UNESCO). Educação para Todos: o compromisso de Dakar. Brasília: UNESCO, CONSED, Ação Educativa, 2001. 
ORGANIZAÇÃO PARA A COOPERAÇÃO E DESENVOLVIMENTO ECONÔMICO (OCDE). Professores são importantes: atraindo, desenvolvendo e retendo professores eficazes. São Paulo: 2006.

Tertiary Education for the Knowledge Society. 2008. Disponível em: <http://www.oecd.org/dataoecd/3/63/41319243.pdf>. Acesso em: $22 / 03 / 2010$.

PERRENOUD, Philipe. 10 Novas Competências para Ensinar. Tradução de Patrícia Chittoni Ramos. Porto Alegre: Artes Médicas Sul, 2000.

RAMOS, Marise Nogueira. A pedagogia das competências: autonomia ou adaptação? São Paulo: Cortez, 2001.

RODRIGUES, José. 0 moderno príncipe industrial: o pensamento pedagógico da Confederação Nacional da Indústria. Campinas (SP): Autores Associados, 1998.

SANTOS, Aparecida de Fátima Tiradentes dos. Teoria do Capital Intelectual e Teoria do Capital Humano: estado, capital e trabalho na política educacional em dois momentos do processo de acumulação. 2009. Disponível em: [http://www.anped.org.br/reuniões/27/gt09/t095.pdf>. Acesso em: 12/04/2010.

SOUZA, Aparecida Neri. Organização e condições do trabalho moderno: precarização do trabalho docente. Seminário da Rede de Pesquisadores sobre Associativismo e Sindicalismo dos Trabalhadores em Educação III, 2011, Rio de Janeiro [Trabalhos apresentados]. Rio de Janeiro.

SOUZA, José dos Santos. Formação do trabalhador no contexto da reconfiguração do trabalho, da produção e dos mecanismos de mediação do conflito de classe. Revista Contemporânea de Educação, vol. 10, n. 20, p. 50-66, julho/dezembro, 2015b.

Desafios do trabalho docente nos Institutos Federais de Educação, Ciência e Tecnologia Brasileiros. In: MAUÈS, Olgaíses Cabral et al. Expansão da educação superior: formação e trabalho docente. Belo Horizonte (MG): Fino Traço, 2015a, pp. 65-85.

UNESCO. Recomendação Relativa à Condição Docente: aprovada pela Conferência Intergovernamental Especial sobre a Condição Docente. Paris, 5 de 
outubro de $1966 . \quad$ Disponível em: <http://unesdoc.unesco.org/images/0015/001515/151538por.pdf>. Acesso em: 10/08/2010.

Recebido em 31-10-2017

Aprovado em 27-11-2017 